\title{
1 Cooperative and aggressive behaviours vary between ranks in anemonefish social
}

\section{2 hierarchies}

3 T Rueger $^{1,2^{*}}$, SJ Heatwole $^{3}$, MY Wong ${ }^{3}$

$4{ }^{1}$ Department of Biology and Marine Program, Boston University, 5 Cummington Mall, Boston, $5 \quad$ MA 02215, USA

$6 \quad{ }^{2}$ Department of Biology, University of Exeter, Penryn, UK

$7 \quad{ }^{3}$ Centre for Sustainable Ecosystem Solutions, School of Earth, Atmospheric and Life Sciences,

8 University of Wollongong, Wollongong, NSW 2522, Australia

\section{Abstract}

Many animal groups consist of individuals organised in dominance hierarchies, based on age, size or fighting ability. Lower ranked individuals often do not reproduce themselves but perform cooperative behaviours to help the reproductive output of dominant individuals or the group as a whole. Theoretical models suggest that individuals of higher rank should show increased amounts of aggressive behaviours, such as aggressions towards other group members, but should decrease the amount of cooperative behaviours, such as brood care or territory maintenance. Most empirical tests of these models focus on insect or mammalian systems where kin selection plays a large role, rather than animals that live in groups of unrelated individuals. Here we use two anemonefish species to test hypotheses of variation in cooperation and aggression with respect to social rank and species, for social systems where group members are unrelated. We assessed the behaviours of each rank in 20 groups of Amphiprion percula and 12 groups of A. perideraion in Kimbe Bay,

21 Papua New Guinea. We also performed a removal experiment to test if cooperative and aggressive 22 behaviours are likely adaptive, i.e., if they change as an individual ascends in rank. Our results 
show differences between the two species, with $A$. percula showing more cooperative behaviours and $A$. perideraion showing more aggressive behaviours, despite them being closely related and sharing a very similar ecology. With respect to both cooperation and aggression we found consistent differences between ranks in both species, with higher ranks performing more aggressive as well as more cooperative behaviours. When we experimentally provided lower ranked individuals (rank 4) an opportunity to ascend in the hierarchy, they showed more aggression and more cooperation in line with our observations for rank 3 individuals. Thus, we show that rank specific behavioural patterns are likely adaptive in anemonefishes and that some model predictions do not hold in systems where kin selection benefits are absent. Rather, future fitness benefits through territory inheritance and group augmentation likely motivate cooperative and aggressive behaviours by subordinates in groups of unrelated vertebrates.

Keywords: sociality, cooperation, coral reef fish, size hierarchy

\section{Introduction}

In many animal societies, groups are organized into dominance hierarchies or queuing systems, based for example on size, fighting ability or age (Cant, 2000; Shreeves \& Field, 2002; Buston, 2003a). Although lower ranked individuals are often not part of the current breeding effort, they are generally capable of reproduction in some taxa, which begs the question of why they tolerate breeding suppression and cooperate. One explanation for this is that subordinates may gain indirect fitness benefits by helping to raise related offspring (Hamilton, 1963; 1964; West-Eberhard, 1975; Queller, 1994). Another reason why lower ranked individuals do not breed is that they have few chances to leave their natal territories and go elsewhere due to harsh environmental conditions or lack of breeding territories (Emlen, 1982), and while subordinates often have the capability to breed themselves, they may not attempt to breed within their group and instead opt to cooperate 
because of social constraints, such as the threat of punishment (Koenig \& Pitelka, 1979; Cant et al., 2010). Additionally, subordinates may eventually inherit the breeding territory and thus gain future fitness benefits by improving the quality of the territory or promoting group augmentation (Wolfenden \& Fitzpatrick, 1978; Kokko \& Johnstone, 1999; Kokko et al., 2001). All of these aspects contribute to the evolution of cooperation and complex societies (reviewed in Bourke, 2011). However, what we do not fully understand is why cooperative effort often varies quite dramatically between individuals, even between those within the same group in the same species (Balshine et al., 2001; Stiver et al., 2006; Clutton-Brock et al., 2008; Wong, 2011).

Theory suggests that individuals in dominance hierarchies should reduce the amount of cooperation and increase the amount of aggression they perform when they are of higher rank and in larger groups (Cant \& Field, 2001; 2005; Cant et al., 2006a; Field et al., 2006). According to several theoretical models, higher ranked subordinates in social groups have a higher probability of future fitness returns from inheriting the dominant position and should therefore put less effort into cooperative behaviours helping the dominants (Cant \& Field, 2001; 2005; Field et al., 2006), and more effort into aggressive behaviours defending their rank (Cant et al., 2006a). However, these models primarily consider kin selection benefits from helping related group members and the associated future fitness benefits from inheriting dominant status in such groups. While kin selection predicts that the degree of relatedness will modify helping effort, several examples exist where relatedness does not explain variability in cooperative behaviour, e.g., in cichlid fishes (Le Vin et al., 2011) and some bird species (Wright et al., 1999; Canestrati et al., 2005). Models have thus far rarely considered future fitness benefits from group augmentation effects of cooperation,

67 where individuals survive or reproduce better in larger groups (Kokko et al. 2001). These effects 
unrelated individuals (Kokko et al., 2001; Kingma et al., 2014). Also, Cant \& Field (2005) show that model predictions do not hold when the cost of helping is higher in lower ranks, which may be common in vertebrates. Besides providing a conceptual underpinning for variation in cooperative behaviours among ranks, empirical tests of theoretical predictions have so far been conducted mainly in insect and mammalian groups where relatedness plays a large role (e.g., Cant et al., 2006b; Cronin \& Field, 2007; Amsalem \& Hefetz, 2011; Thavaraja et al., 2014, Jandt et al., 2014).

In vertebrates with dominance hierarchies where relatedness does not play a large role, such as many fish species, variation in cooperative or aggressive behaviours more likely depend on dominance rank and group size. Aggressive behaviours in some fish groups have been found to vary with dominance rank (Fricke \& Fricke 1977, Colleter \& Brown, 2011; Dey et al. 2012), although rank specific studies are still rare. In male rainbowfish (Melanotaenia duboulayi) various behaviours have been found to covary with the individual's position in the size-based dominance hierarchy, with dominant fish being more aggressive, bolder and more active (Colleter \& Brown, 2011). Cooperative behaviours by subordinates in complex fish groups have primarily been studied in cooperative breeding freshwater cichlids (Taborsky \& Limberger, 1981), where different sized subordinates have been found to be task specialized, e.g., smaller subordinates performed eggpredator defence more frequently, whereas larger subordinates spend more time digging sand from

87 the breeding shelter (Bruintjes \& Taborsky, 2011). While most group-living marine fishes do not provide alloparental brood care, other behaviours beneficial to the group or the territory have been observed in several taxa, such as defence against egg predators, territory maintenance and cleaning 90 (Ross, 1978; Fricke, 1979; Iwata \& Manbo, 2013), though these behaviours have rarely been 91 quantified or studied for specific ranks. Thus, quantifying cooperative behaviours as well as 
aggression in a wider range of vertebrate species, and considering the two behaviour types at the same time will give a better understanding about the differences between ranks in dominance hierarchies and thus broaden our understanding of sociality in general.

Here we use anemonefishes (genus Amphiprion) to examine differences in cooperative and aggressive behaviours among ranks and to experimentally test whether these differences are likely to be adaptive, i.e., whether there are predictable changes in behavioural patterns as an individual changes rank. Anemonefishes form symbiotic relationships with their host anemone (Fautin, 1992). They are sequential hermaphrodites and form strict size hierarchies within groups of unrelated individuals, where groups typically consist of one dominant breeding pair and zero to five unrelated subordinates (Fricke, 1979; Fautin, 1992; Buston, 2004a; Buston \& Cant 2006). The female is always the largest individual (rank 1), the male is the second largest (rank 2), and all other fish are non-breeders that get progressively smaller (rank 3, rank 4, etc.) (Fricke \& Fricke, 1977; Buston, 2003a). Rank ascension only happens when a higher rank disappears (Buston, 2003a; Buston, 2004b). Although subordinate anemonefishes are not known to help dominants rear offspring, alternate metrics of cooperation, namely territory defence (chasing predators away from the group) (Ross, 1978; Fricke; 1979; Iwata \& Manbo, 2013) and territory maintenance (cleaning the anemone) (Mariscal 1966) can be observed and quantified. Specifically, we focused on two closely related anemonefish species common in the Indo-Pacific; Amphiprion percula and A. perideraion. While the two species both primarily inhabit the same anemone species, Heteractis magnifica, and are otherwise ecologically similar, differences in their behaviours have recently been reported. A. perideraion, particularly individuals at the top of the dominance hierarchy, have been observed leaving their anemone and forcefully taking over groups of $A$. percula (Rueger et al., 2018). In contrast, $A$. percula has been shown to not leave the confines of their host, even to 
115 bridge small distances (Branconi et al., in press). Thus, there is the potential for different costs and benefits of within-group rank ascension, making these two species appropriate for testing the

117 robustness of current theory.

119 To investigate whether and how cooperative and aggressive behaviours vary between social ranks, we used a combination of field observations and experimental techniques to test the following specific hypotheses in $A$. percula and A. perideraion: 1) Cooperative and aggressive behaviours will differ depending on individual dominance rank but not species; 2) In line with current theoretical predictions, the frequency of cooperative behaviours will decrease and the frequency of aggressive behaviours will increase when individuals are experimentally promoted in rank.

\section{Methods}

The study was conducted on inshore reefs near Mahonia Na Dari Research and Conservation

127 Centre in Kimbe Bay, Papua New Guinea (5³0’ S, $150^{\circ} 05^{\prime}$ E), in September and October 2018 and May 2019. All fieldwork was conducted using SCUBA.

We used 20 groups of $A$. percula, and 12 groups of $A$. perideraion for observations and groups, most $(\mathrm{n}=16)$ were associated with the anemone species Heteractis magnifica, while the rest were associated with Stichodactyla gigantea $(n=4)$. This accurately reflects the observed relative distribution of host occupancy for the population on inshore reefs in Kimbe Bay (Chausson et al. 2018). All $A$. perideraion groups $(\mathrm{n}=12)$ were associated with $H$. magnifica hosts. For $A$. 
comprised either four fish $(n=9)$ or five fish $(n=3)$. The difference in sample size between species was due to a lack of available groups of $A$. perideraion with 4-5 individuals. Half of the $A$. percula groups $(\mathrm{n}=10)$ were observed breeding during the experiment, whereas few groups of $A$. perideraion were observed breeding $(\mathrm{n}=3)$.

\section{Rank ascension experiment}

To experimentally examine variability in cooperative and aggressive behaviours between ranks we removed the rank 3 individual from half of the groups of $A$. percula $(n=10)$ and $A$. perideraion $(n=6)$ (i.e., treatment groups; Figure 1) to give the rank 4 an opportunity for rank ascension. From the other half of the groups (i.e., control groups, Figure 1) we removed the lowest ranking individual (rank 4 or 5 depending on the group size). This was done to control for the reduced number of group members and to be able to compare rank 4 behaviours from the treatment to rank 3 behaviours from the control groups. During the experiment, the removed individuals were held in aerated sea water tanks at Mahonia Na Dari Research and Conservation Centre, where they were provided with shelter and fed twice a day with dried brine shrimp (Omega One, freeze dried brine shrimp) and fish pellets (New Life Spectrum, marine fish food $1 \mathrm{~mm}$ pellets). The removed fish was then replaced back into its original group. Groups were filmed with a GoPro Hero5 for 12 minutes from a 1.5-2.5m distance at six time points: 1 . Prior to removal of the rank 3 (or rank 4 in control groups), 2. Immediately after removal of the fish, 3. 24 hrs post-removal, 4. 48 hrs postremoval, 5. Immediately after the reintroduction of the removed individual, 6. 24 hrs postreintroduction. To account for any ecological effects of anemone size, soft tailor's tape was used to measure the long and short diameter of the anemone's tentacle crown. Anemone size was then calculated as the area of an ellipse $(\pi \times$ major axis $/ 2 \times$ minor axis $/ 2)$. 

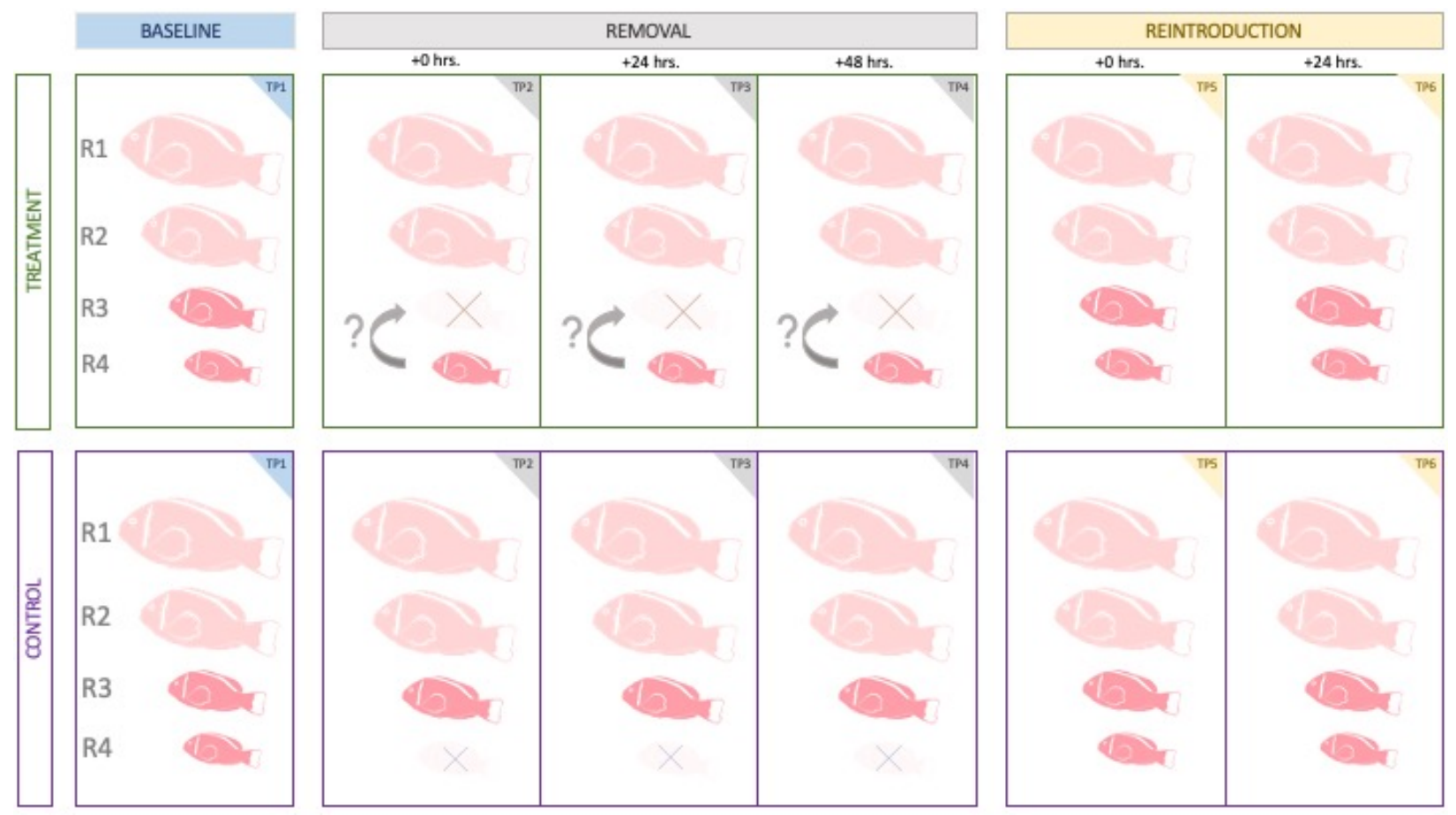

Figure 1. Experimental design of the rank ascension experiment conducted with groups of $A$. percula $(\mathrm{n}=20)$ and $A$. perideraion $(\mathrm{n}=12)$ in Kimbe Bay, Papua New Guinea. In treatment groups, the rank 3 (R3) was removed allowing for rank ascension by rank 4 (R4). In control groups, the lowest ranked group member was removed to control for group size reduction whilst preventing rank ascension by any group member. $\mathrm{TP}=$ Time point. $\mathrm{R}=$ rank.

Video analysis

A total of $153.8 \mathrm{hrs}$ of video footage was analysed. Behaviours were scored using the BORIS program (Friad \& Gamba, 2016) and following an ethogram based on Wong et al. (2013) (Supplemental Material Table 1). For each video, 10 of the 12 minutes of footage was watched with 1 minute at the start and end of each video being discarded to account for disturbance created by the diver approaching to handle the video camera. To account for differences in the time each fish was visible in the frame, the time each fish spent out of sight during the recording was noted and all behaviours were analysed per minute of observation. Each video was watched multiple times so that every individual in the group was scored separately and continuously in one sequence 
175

176

177

178

179

180

181

182

183

184

185

186

187

188

189

190

to make behaviour scores as accurate as possible. Behaviours scored fell into four broad categories:

1) aggressive, 2) submissive, 3) neutral, 4) cooperative (Table 1). For all interactive behaviours,

the individual receiving the submission or aggression was recorded. Behaviours were scored for ranks 1 to 5 .

Table 1. Broader behavioural categories used in the analysis for A. percula and A. perideraion. For a more detailed description of behaviours refer to the ethogram in supplemental material.

\section{Behavioural category}

Aggression

Submission

Neutral

Cooperation

\section{Description}

All aggressive behaviours among group members, e.g., chases, bites.

All submissive behaviours among group members, e.g., body shake.

When group members were within one body length of each other but did not display aggression or submission.

Behaviours beneficial to the group (e.g., aggression towards egg predators, aggression towards food competitors, parental care) or beneficial to the anemone (e.g., anemone cleaning/manipulating, aggression towards anemone predators)

\section{Data analysis}

We used R (R Core Team, 2019) and the lme4 package (Bates, Maechler \& Bolker, 2012) to perform linear mixed model analysis (LMM). We used Akaike Information Criterion (AIC) (Sakamoto et al., 1986) for model selection. If $\triangle \mathrm{AIC}$ was below 2, a likelihood ratio test was performed to decide which model was the best fit, with preference for the simpler model. Significance tests for LMMs were performed by likelihood ratio tests of the full model with the effect in question against the model without the effect. No obvious deviations from normality and homoscedasticity were detected by visually inspecting the residual plots. Models were also tested

for outliers and collinearity between variables with performance (Luedecke et al., 2020). No outliers or high variance inflation factors (VIF) were detected in any of the best-fit models. 
191 Conditional and marginal $\mathrm{R}^{2}$ were calculated using Nakagawa's $\mathrm{R}^{2}$ in performance (Nakagawa \&

192 Schielzeth, 2013; Johnson, 2014; Nakagawa, Johnson \& Schielzeth, 2017).

193 As response variables, behaviours were analysed as behaviours per minute of observation to 194 account for differences in observation time for each fish. Behaviours/min was log transformed to 195 account for a non-normal distribution (left screw due to many zero values).

$\underline{\text { Behavioural differences between ranks, species and group sizes }}$

To test the differences in behaviours between ranks and species, we fitted four separate LMMs for each behavioural category: aggression, submission, neutral behaviours and cooperation (Table 1). The corresponding response variables were aggression/min, submission $/ \mathrm{min}$, neutral $/ \mathrm{min}$ and cooperation $/ \mathrm{min}$. For cooperation/min we performed model selection excluding parental

201 behaviours (see Suppl. Table 1 for definition), since those were only recorded in A. percula. Fixed

202 factors tested were fish species (A. percula, A. perideraion) and individual rank in the group 203 hierarchy (ranks 1-5). Covariates tested included number of fish in each group (group size), anemone species (H. magnifica, S. gigantea) and anemone size (tentacle crown surface area of the anemone in $\mathrm{cm}^{2}$ ). Model selection was performed as described above. Group ID was used as a random variable to account for non-independence of individual behaviours within the same group.

207 In the model with submission/min as the response variable, the random term variance component 208 was zero and conditional $\mathrm{R}^{2}$ could not be calculated. This had no effect on the model components 209 reported here (Pasch, Bolker, \& Phelps, 2013). To be consistent with the other models in this 210 section and to not influence AIC values for the model selection process, we left the random 211 variable in the model.

212 Rank ascension experiment 
213 To test differences in behaviours in the treatment and control groups and between different time

214 points (Figure 1), separate LMMs were fitted for each species (A. percula, A. perideraion) and

215 each rank in the group hierarchy. Since rank 3 individuals were absent from time points $2-4$ in the

216 treatment groups and rank 4 individuals were absent from time points 2-4 in the control groups,

217 the full cross model (including rank, treatment group and time point as fixed factors and

218 interactions) was only used to examine specific contrasts (see below). For the species and rank

219 specific models, only ranks 1-4 were tested since there was limited data available for rank 5 . The

220 three behavioural categories of primary interest were used as response variables (aggression/min,

$221 \mathrm{submission} / \mathrm{min}$, cooperation/min). Fixed factors tested were time point (time points 1-6 of the

222 experiment, Figure 1), and treatment (treatment, control). Covariates tested were group size,

223 anemone size and anemone species. Model selection was performed as described above. Group ID

224 was used as a random variable to account for repeated measures of the same individuals. In two

225 models (A. perideraion, rank 3, aggression/min and submission/min), the random term variance

components reported here (Pasch, Bolker, \& Phelps, 2013). To be consistent with the other models

in this section and to not influence AIC values for the model selection process, we left the random

229 variable in the model.

To further investigate variability due to rank, we compared the behaviour of ranks 3 and 4 directly

231 in two ways. First, we compared the behaviour of the rank 3 in control groups (rank 4 removed)

232 to the behaviour of the ascended rank 4 in treatment groups (rank 3 removed) using post-hoc tests on the difference in behaviours between time points using the emmeans package (Length, 2020).

234 Second, we compared rank 3 behaviour during the baseline time point 1 (in control and treatment) 235 and during the time points 2-4 (in control) to rank 4 behaviour during time points 2-4 (treatment). 
This comparison is important because during the removal, rank 3 in the control groups and rank 4 in the treatment groups effectively occupy the same position in the hierarchy (position 3). For this comparison, we built a full cross model (including all two-way and three-way interactions) with rank, treatment and time point as fixed factors, and group ID as a random effect. The model was checked for fit, collinearity and outliers as described above. We then used emmeans to build a custom contrast matrix for the above-mentioned comparisons. P-values were adjusted for multiple

242 testing using a multivariate $t$ distribution correction.

\section{Results}

Behavioural differences between ranks and species

There were significant differences in the frequency of aggressive behaviours between ranks $\left(\chi_{(4)}=\right.$ 145.080, $\mathrm{p}<0.001)$, species $\left(\chi_{(1)}=9.540, \mathrm{p}=0.002\right)$, and group sizes $\left(\chi_{(1)}=14.730, \mathrm{p}<0.001\right)$

248 (Figure 2). The fixed effects explained $22.4 \%$ of the variance $\left(\mathrm{R}^{2}{ }_{\mathrm{c}}=0.254, \mathrm{R}_{\mathrm{m}}=0.224\right)$. The best

249 fit model did not include anemone size or anemone species, or interactions between any fixed

250 effects. The model estimates show that for each species, ranks 1-3 were more aggressive than the

251 lower ranks (Figure 3a), and on average, rank 4 showed 33\% ( $\pm 5 \%$ s. e.) less aggression than rank

252 1. An increase in group size by one fish increased mean aggressions per minute by $9 \%( \pm 2 \% \mathrm{~s}$.

e.). Looking specifically at how aggressive behaviours were directed towards each group member, ranks 1 and 2 in $A$. perideraion groups were more aggressive towards lower ranks than were ranks

2551 and 2 in $A$. percula groups (Figure 4). Overall, aggression was $14 \%$ ( $\pm 5 \%$ s. e.) higher in $A$. 256 perideraion compared to A. percula (Figure 2). 
There were significant differences in the frequency of submissive behaviours between ranks $\left(\chi_{(4)}\right.$ $=331.44, \mathrm{p}<0.001)$. The fixed effects explained $34.7 \%$ of the variance $\left(\mathrm{R}^{2} \mathrm{c}=\mathrm{NA}, \mathrm{R}_{\mathrm{m}}^{2}=0.347\right)$. The best fit model did not include anemonefish species, group size, anemone size or anemone species, or any interactions. The most submissive behaviours were performed by rank 3 and the least by rank 1, with a mean difference in submission frequency between the two of $86 \%( \pm 5 \%$ s.e.) (Figure 3b). Most submissions by ranks 2-4 were performed towards the rank immediately above them (A. percula: rank 2 to rank 1, 100\%, rank 3 to rank 2, 53\%, rank 4 to rank 3,58\%; $A$. perideraion: rank 2 to rank 1, 100\%, rank 3 to rank 2, 53\%, rank 4 to rank $3,63 \%$ ).

\section{Neutral}

There were significant differences in the frequency of neutral social behaviours between ranks $\left(\chi_{(4)}\right.$ $=497.57, \mathrm{p}<0.001)$. The fixed effects explained $45.9 \%$ of the variance $\left(\mathrm{R}^{2}{ }_{\mathrm{c}}=0.505, \mathrm{R}_{\mathrm{m}}^{2}=0.459\right)$. The best fit model did not include anemonefish species, group size, anemone size or anemone species, or any interactions. Neutral behaviours among group members were primarily observed between rank 1 and rank 2 in both species and consisted primarily of close proximity (Figure 3c).

\section{Cooperation}

There were significant differences in the frequency of cooperative behaviours between ranks $\left(\chi_{(4)}\right.$ $=140.950, \mathrm{p}<0.001)$ and species $\left(\chi_{(1)}=12.753, \mathrm{p}<0.001\right)$. The best fit model did not include group size, anemone size, anemone species or any interactions. The fixed effects explained $20.5 \%$ of the variance $\left(\mathrm{R}^{2}{ }_{\mathrm{c}}=0.263, \mathrm{R}_{\mathrm{m}}{ }_{\mathrm{m}}=0.205\right)$. Cooperative behaviours were observed at a $26 \%( \pm 8 \%$ s.e.) higher rate in A. percula compared to A. perideraion (Figure 2). For each species, ranks 1-3 were more cooperative than the lower ranks (Figure 3d). The specific cooperative behaviours performed also differed between ranks (Figure 5). For example in A. percula, interaction with the 

respectively) (Figure 5).

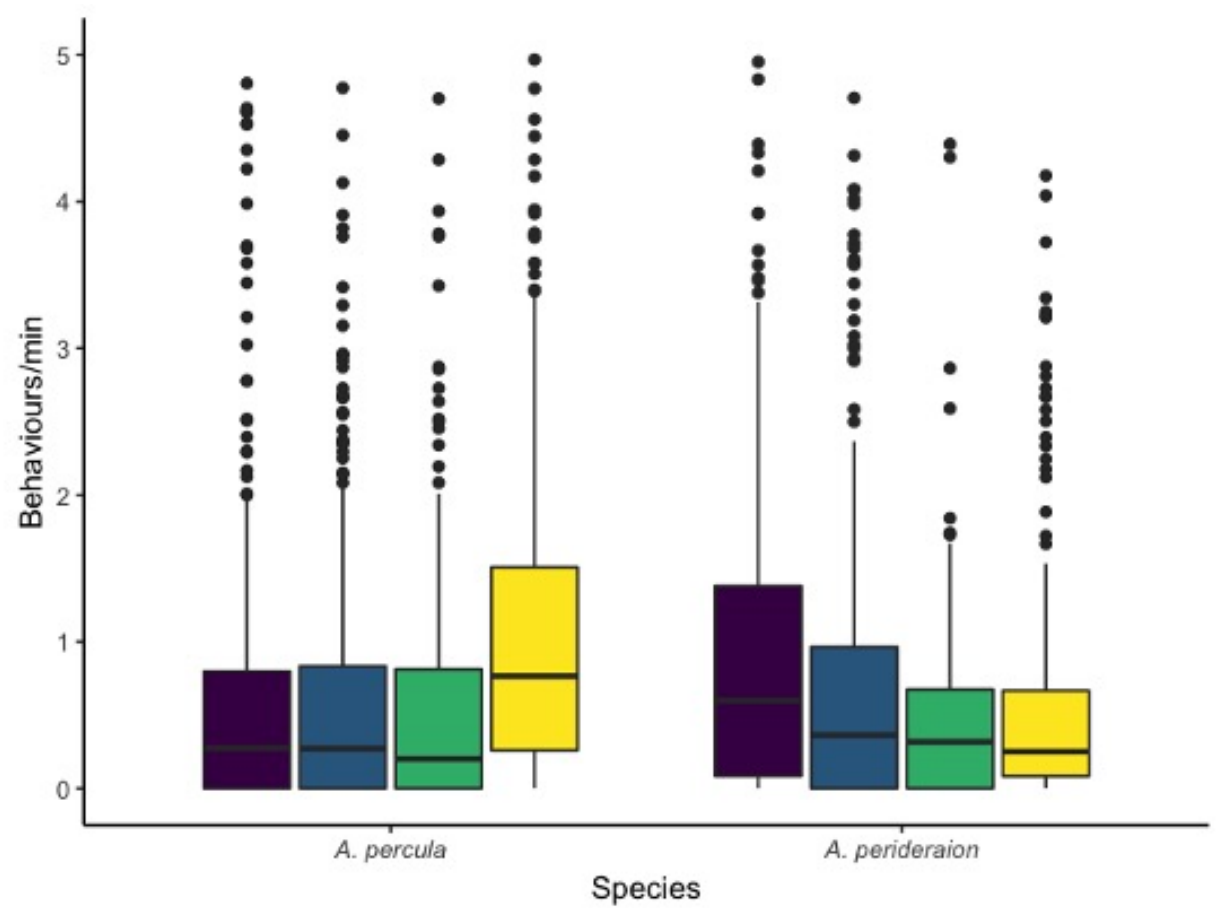

Behavioural category

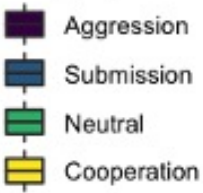

Figure 2. Behavioural frequencies (behaviours/min) for two species of anemonefishes 286 (Amphiprion percula and A. perideraion) in Kimbe Bay, Papua New Guinea (central bar: median; boxes: lower and upper quartiles; whiskers: +/-1.5*IQR (interquartile range)). Observed behaviours were pooled into four categories (see Table 1). 

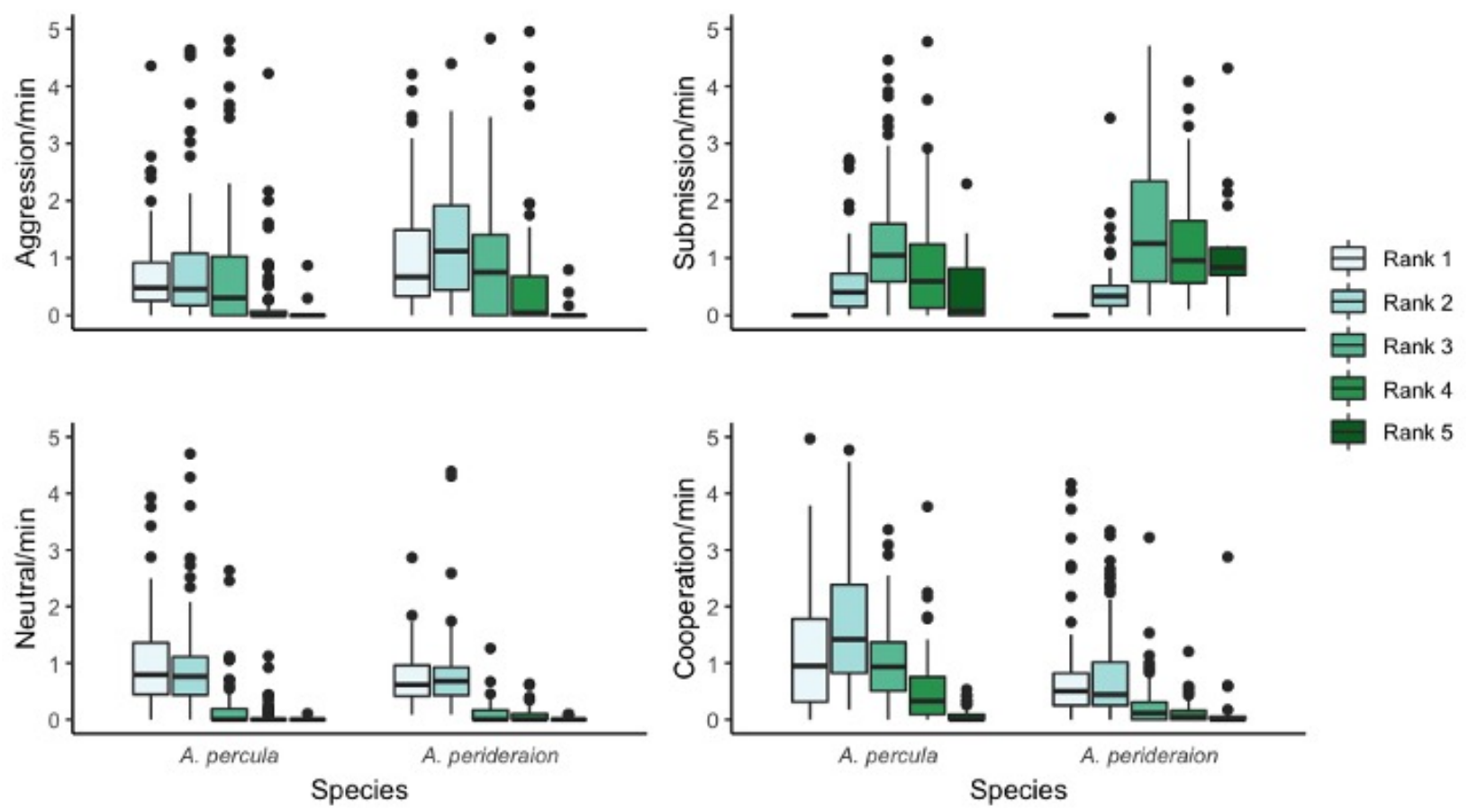

Figure 3. Behavioural frequencies (behaviours/min) for each rank (1-5) in the size hierarchy in two species of anemonefishes (Amphiprion percula and A. perideraion) (central bar: median; boxes: lower and upper quartiles; whiskers: $+/-1.5^{*} \mathrm{IQR}$ (interquartile range)). Observed behaviours were pooled into four categories (see Table 1); a) Aggression; b) Submission; c) Neutral; d) Cooperation.

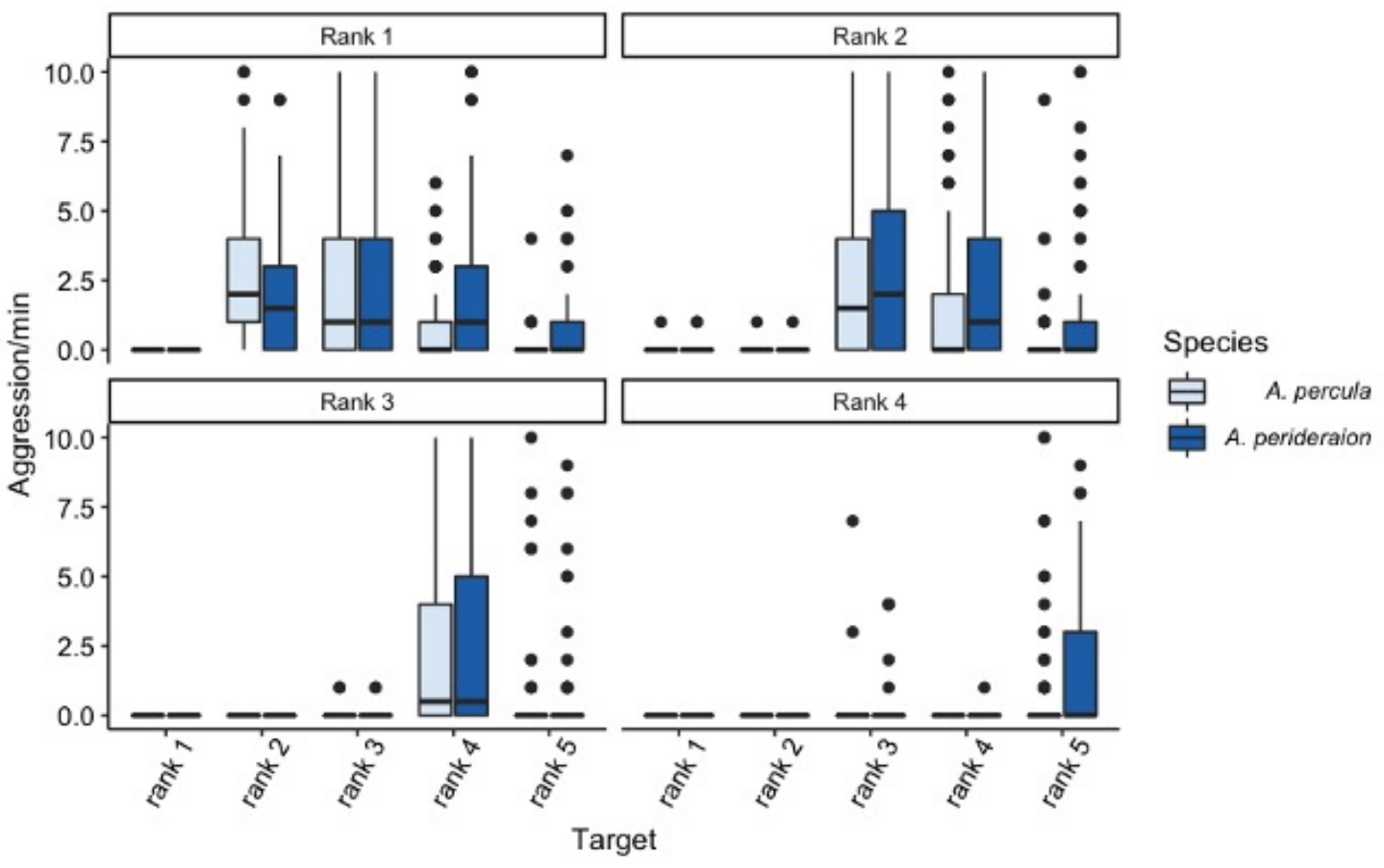


Figure 4. Number of aggressive behaviours per minute (Aggression/min) recorded for rank 1 to rank 4 in two species of anemonefishes (Amphiprion percula $(\mathrm{n}=20)$ and A. perideraion $(\mathrm{n}=12)$ (central bar: median; boxes: lower and upper quartiles; whiskers: $+/-1.5^{*} \mathrm{IQR}$ (interquartile range)). The individual the aggression was directed towards was recorded (ranks 1- 5).
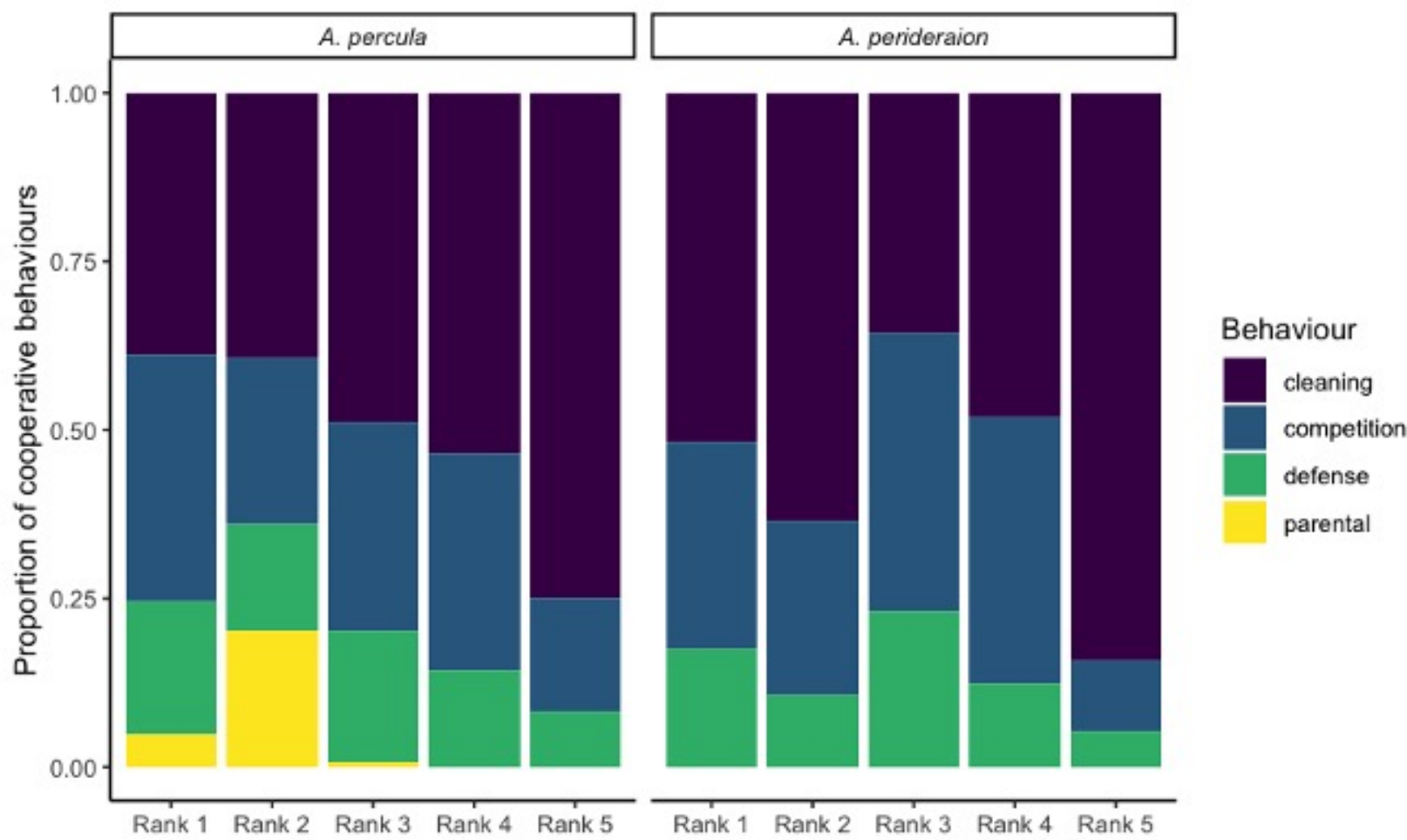

Figure 5. Proportion of cooperative behaviours for each rank in A. percula and A. perideraion. Behaviours include 'cleaning' (interactions with the anemone including cleaning, massaging, biting), 'competition' (aggressive behaviours towards food competitors such as other Pomacentridae), 'defense' (aggressive behaviours towards egg predators such as Labridae or anemone predators such as Chaetodontidae), and 'parental' (when the fish is within one body length of an egg clutch and is fanning or mouthing the brood).

\section{Rank ascension experiment}

Aggression

Out of 32 removed fish, none were evicted from their groups upon reintroduction. All reintroduced remain close to the anemone. 
314 For both species, the frequency of aggressive behaviours towards other group members differed between time points of the experiment for all ranks tested (Table 2, Figure 6). For A. percula, the best fit model for 'aggressions/min' for ranks 1-3 only included time point as a fixed term, and did not include treatment, group size or any interactions. For A. perideraion, the best fit model for rank 1 and rank 2 only included time point as a fixed term, and did not include treatment, group size or any interactions. For A. perideraion rank 3, the best fit model also included group size, with aggressions rising by an estimated $7 \%$ ( $\pm 3 \%$ s. e.) for an additional group member. For rank 4 of both species, the best fit model included time point, treatment, group size, as well as an interaction between time point and treatment, all of which were significant (Table 2). while rank 4 was removed (TP2-4) compared to the baseline time point (TP1) (Suppl. Figure 1, TP1 vs TP2, $A$. percula: estimate $=-0.322,95 \%$ confidence interval (c. i. $)=-0.606,-0.038 ; A$. perideraion: estimate $=-0.809$, c. $\mathrm{i} .=-1.341,-0.279)$. In the $A$. percula treatment groups, rank 4 showed slightly increased aggression while rank 3 was removed, though this was not significant, while in the $A$. perideraion treatment groups rank 4 showed no change (Suppl. Figure 1). treatment groups showed a significantly lower frequency of aggression in both species (Suppl. Figure 1, rank 3 control TP1 vs rank 4 treatment TP2, . percula: estimate $=-0.385$, c. i. $=-0.718$, 0.051; A. perideraion: estimate $=-0.717$, c. $\mathrm{i} .=-1.101,-0.334)$. Levels of aggression in the treatment group rank 4 while rank 3 was removed were not significantly different compared to levels of aggression in the control group rank 3 while rank 4 was removed (Suppl. Figure 1). 
rank 4 in the treatment groups showed an estimated $67 \%( \pm 13 \%$ s. e. $)$ higher rate of aggression in A. percula and a $112 \%( \pm 14 \%$ s. e.) higher rate of aggression in A. perideraion, compared to the baseline time point 1 (Suppl. Figure 1). All group members directed a large proportion of aggressions towards the reintroduced fish at time point 5 in the treatment groups (immediately after rank 3 introduction) (A. percula: rank 1,71\%, rank 2, 84\%, rank 4,72\%, A. perideraion: rank $1,63 \%$, rank $2,83 \%$, rank $4,95 \%$ ). In the control groups at time point 5 , a large portion of aggressions were directed towards the newly reintroduced rank 4 compared to the baseline time point 1 (A. percula: rank 1: TP1, 17\%, TP5, 24\%; rank 2: TP1, 15\%, TP5, 39\%; rank 3: TP1, 100\%, TP5, 97\%; A. perideraion: rank 1: TP1, 42\%, TP5, 60\%; rank 2: TP1, 26\%, TP5, 40\%; rank 3: TP1, 84\%, TP5, 96\%).

Table 2. Best fit models for each rank of A. percula and A. perideraion with aggressive behaviours towards other group members per minute ('aggression/min') as the response variable. Fixed terms tested included time point of the experiment ('time point'), treatment group ('treatment'), and interactions, with number of fish in each group ('group size') tested as a covariate. Group ID was included as a random variable to account for repeated measures. Significance was tested using likelihood ratio tests.

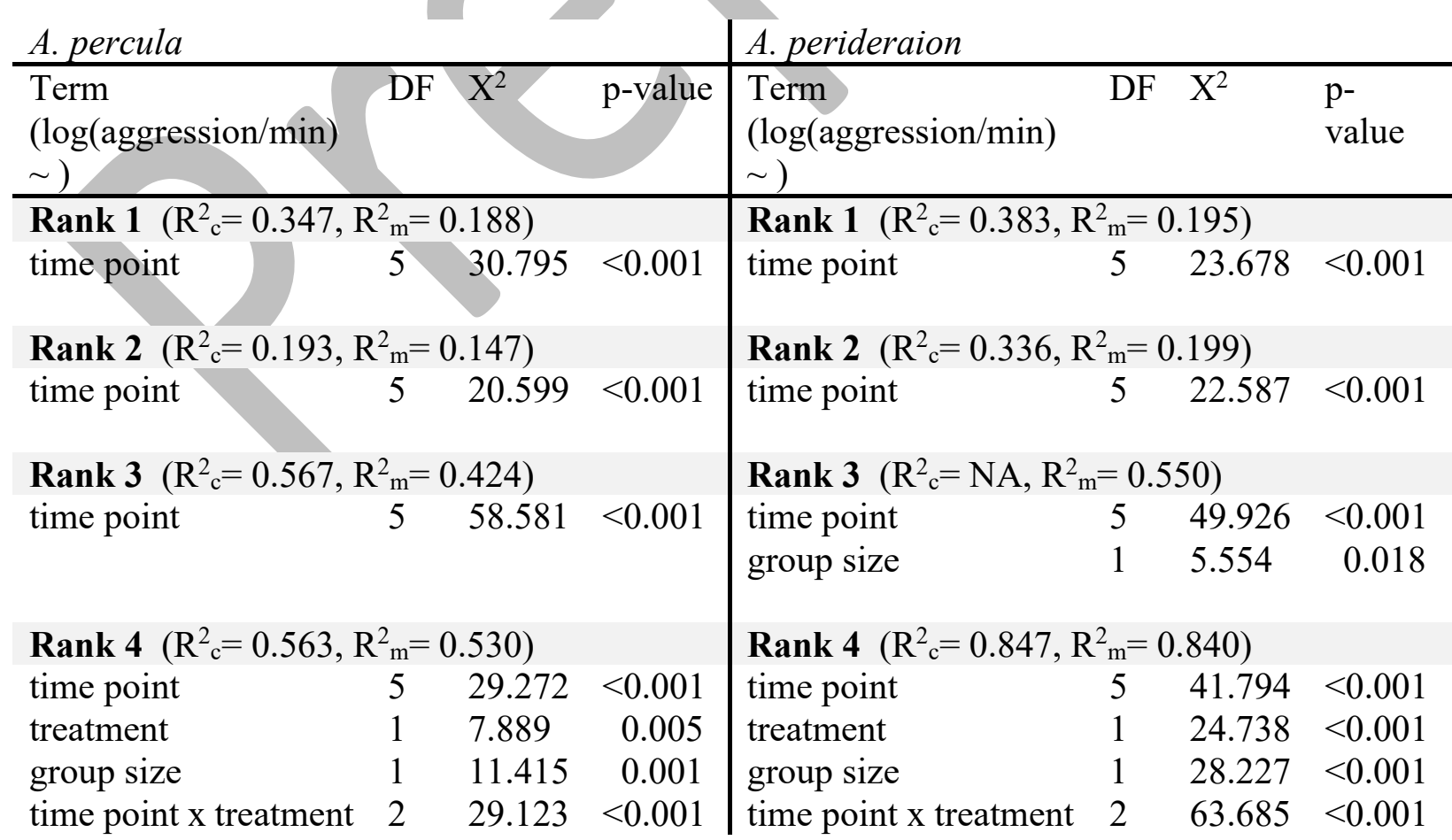




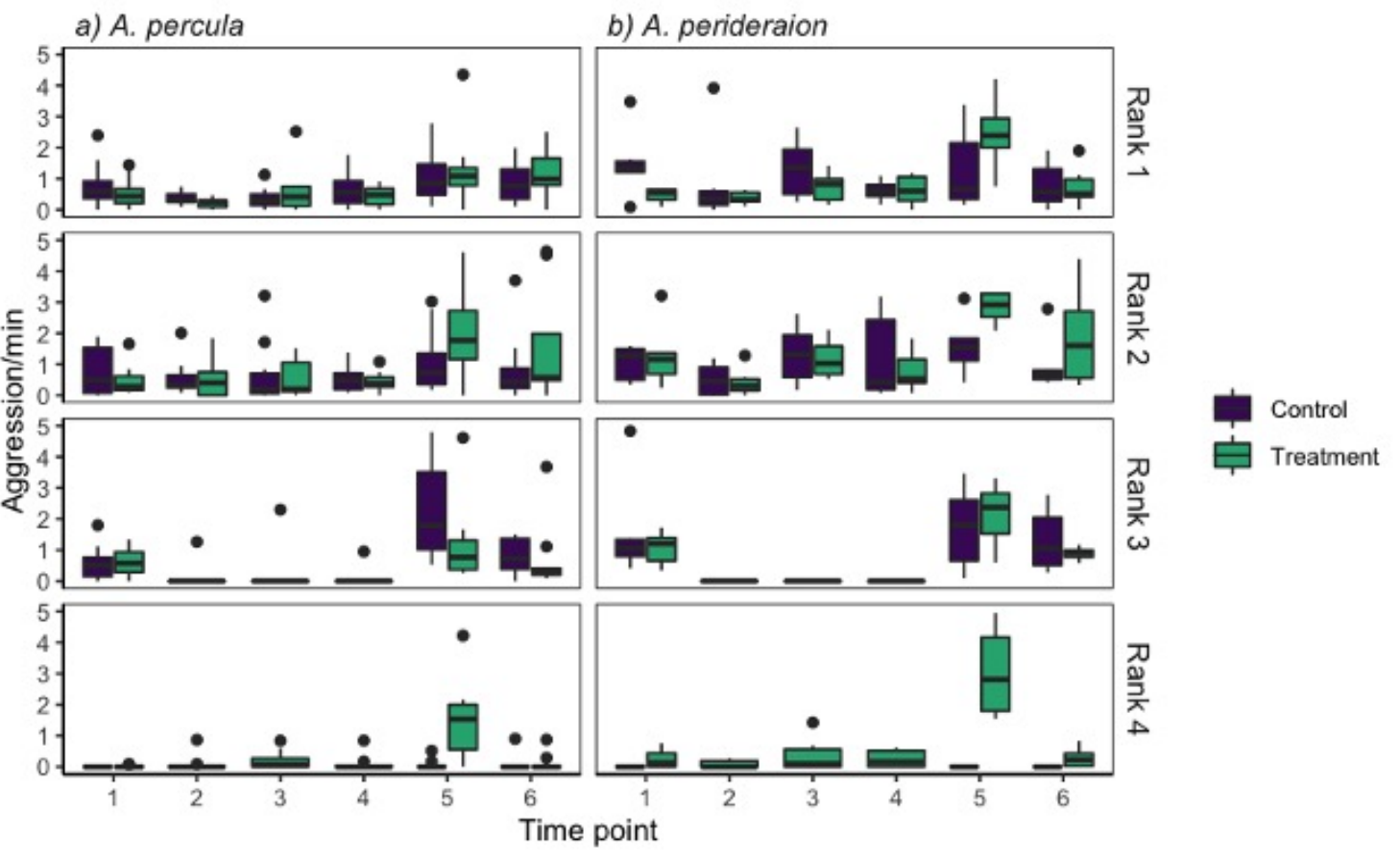

355

356

357

358

359

360

361

362

363

364

365

366

Figure 6. Aggressive behaviours per minute ('Aggression/min') in groups of a) Amphiprion percula $(\mathrm{n}=20)$ and $\mathrm{b})$ A. perideraion $(\mathrm{n}=12)$, for each rank in the size hierarchy (rank 1-4), time point (1-6) and treatment group (purple: Control, green: Treatment) of the rank ascension experiment (central bar: median; boxes: lower and upper quartiles; whiskers: $+/-1.5 * I Q R$ (interquartile range)).

\section{Submission}

For $A$. percula, the frequency of submissive behaviours by ranks 2 and 3 did not differ with treatment or time point of the experiment (Figure 7a). The best fit model for ranks 2 and 3 was the null model, with the random factor (Group ID) explaining 15\% and 5\% of the variance respectively (rank $2 \mathrm{R}^{2}{ }_{\mathrm{c}}=0.147$, rank $3 \mathrm{R}^{2}=0.049$ ). For rank 4 A. percula, the best fit model included only time point as the fixed variable, which explained $23 \%$ of the variance $\left(\mathrm{R}^{2} \mathrm{c}=0.259\right.$, $\mathrm{R}^{2}{ }_{\mathrm{m}}=0.232$ ). For $A$. perideraion, the frequency of submissive behaviours did not differ with treatment or time point of the experiment for any rank (Figure 7b). The best fit model was the 
null model for ranks $2-4$, with the random factor (Group ID) explaining $8 \%$ and $45 \%$ of the variance in rank 2 and 4 respectively (rank $2 \mathrm{R}_{\mathrm{c}}^{2}=0.077$, rank $3 \mathrm{R}_{\mathrm{c}}{ }_{\mathrm{c}}=\mathrm{NA}$, rank $4 \mathrm{R}_{\mathrm{c}}^{2}=0.449$ ).

For both species, there were no significant differences in submissive behaviours in rank 4 during the treatment (Suppl. Figure 2), but the main target of submissions changed from rank 3 at time point 1 (A. percula $53 \%$, A. perideraion $66 \%$ of submissive behaviours) to rank 2 during the time rank 3 was removed at time points 2 (A. percula 67\%, A. perideraion 63\%), 3 (A. percula 56\%, $A$. perideraion 58\%) and 4 (A. percula 62\%, A. perideraion 67\%). In A. percula, at time points 5 and 6 in the treatment, rank 4 showed submissive behaviours towards ranks 1, 2 and 3 (TP5: 27\%, 46\% and 27\% respectively; TP6: $30 \%, 30 \%$ and 40\% respectively). In A. perideraion, at time point 5 in the treatment, rank 4 showed similar frequencies of submissive behaviours to rank 1 and 2 (44\% and $39 \%$ respectively), and at time point 6 , most were directed at rank 3 once again (70\%). Rank 3 did not change the frequency or target of submissive behaviours during the control in either species (Suppl. Figure 2). Spikes in submissive behaviours were recorded for rank 4 and rank 3 when the fish were reintroduced at time point 5. At reintroduction, rank $4 \mathrm{~A}$. percula performed a mean of $27 \%$ ( $\pm 8 \%$ s. e.) more submissions compared to time point 1 (Figure $7 \mathrm{a})$. In $A$. perideraion overall, rank 4 showed less submissive behaviours in the treatment group than rank 3 in the control group during the early treatment time points, whereas later treatment time points were not significantly different from the rank 3 control (Suppl. Figure 2). 


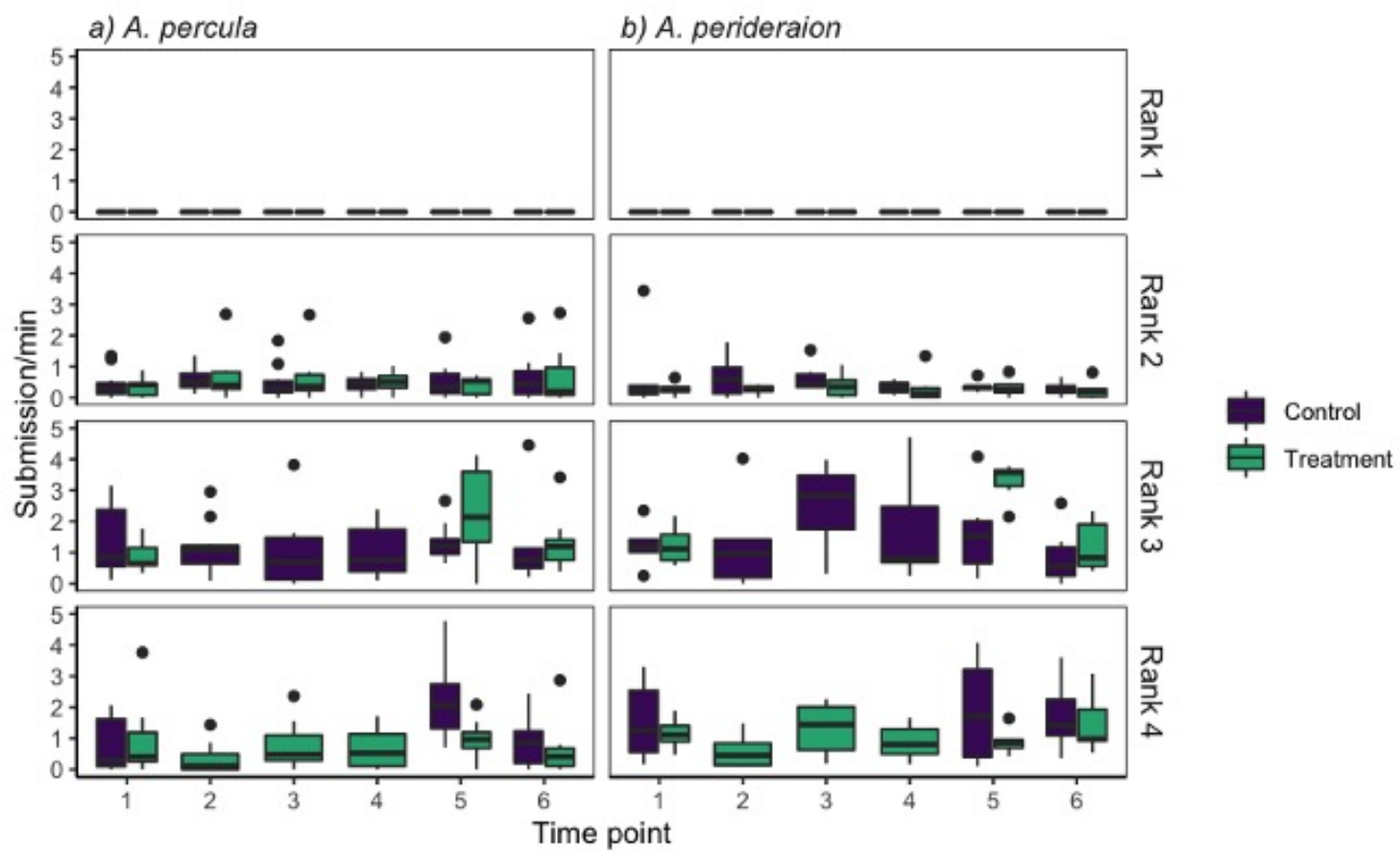

Figure 7. Submissive behaviours per minute ('Submission/min') in groups of a) Amphiprion percula $(\mathrm{n}=20)$ and $\mathrm{b})$ A. perideraion $(\mathrm{n}=12)$, for each rank in the size hierarchy (rank 1-4), time point (1-6) and treatment group (purple: Control, green: Treatment) of the rank ascension experiment (central bar: median; boxes: lower and upper quartiles; whiskers: $+/-1.5 * I Q R$

392 (interquartile range)).

Cooperation

For ranks 1-3 in both species, the frequency of cooperative behaviours did not differ with treatment which in $A$. percula explained $29 \%, 38 \%$, and $18 \%$ of the variance respectively $\left(\right.$ rank $1 \mathrm{R}^{2}{ }_{\mathrm{c}}=0.287$, $\operatorname{rank} 2 \mathrm{R}_{\mathrm{c}}^{2}=0.383$, rank $3 \mathrm{R}_{\mathrm{c}}^{2}=0.184$ ), and in $A$. perideraion explained $15 \%, 12 \%$, and $3 \%$ of the variance respectively (rank $1 \mathrm{R}_{\mathrm{c}}^{2}=0.148$, rank $2 \mathrm{R}_{\mathrm{c}}^{2}=0.124$, rank $3 \mathrm{R}_{\mathrm{c}}^{2}=0.033$ ). For rank 4 in both species, the best fit model included only treatment as the fixed variable. The frequency of cooperative behaviours per minute of observation for rank 4 was $21 \%$ ( $\pm 10 \%$ s. e.) higher in the treatment group compared to the control group in $A$. percula $\left(\chi_{(1)}=4.394, \mathrm{p}=0.036\right)$, and $8 \%( \pm$ 
$4 \%$ s. e.) higher in the treatment group compared to the control group in $A$. peridareion $\left(\chi_{(1)}=\right.$ 4.887, $\mathrm{p}=0.027)$. 'Treatment' explained $5.6 \%$ of the variance in $A$. percula $\left(\mathrm{R}^{2}{ }_{\mathrm{c}}=0.108, \mathrm{R}^{2} \mathrm{~m}=\right.$ $0.056)$ and $7.5 \%$ of the variance in A perideraion $\left(\mathrm{R}_{\mathrm{c}}^{2}=0.080, \mathrm{R}_{\mathrm{m}}^{2}=0.075\right)$.

In $A$. percula cooperation in rank 4 was highest at time point 4 ( $48 \mathrm{~h}$ after removal of rank 3 ), when cooperative behaviours were performed on average at a 2.8 times higher rate compared to the baseline time point 1 (mean cooperation $/ \min \pm$ s. e., time point 1: $0.35 \pm 0.1$; time point 4: $0.96 \pm$ 0.3). In particular, 'cleaning' behaviours increased the most, which made up $30 \%$ of cooperative behaviours at baseline time point 1 and $50 \%$ at treatment time point 3 . In $\mathrm{A}$. perideraion, cooperation in rank 4 in the treatment was highest at time point 3 (24h after removal of rank 3 ), when cooperative behaviours were performed on average at a 1.8 times higher rate compared to the baseline time point 1 (mean cooperation $/ \mathrm{min} \pm \mathrm{s}$. e., time point $1: 0.21 \pm 0.05$; time point 3 : $0.37 \pm 0.16$ ). The behaviour that increased the most for $A$. perideraion rank 4 was also 'cleaning', which made up $40 \%$ of cooperative behaviours at baseline time point 1 and $57 \%$ at treatment time point 3. In both species, post-hoc tests showed no significant differences between time points for the rank 4 in the treatment groups (baseline TP1 compared to TP2-4 when rank 3 is removed and rank ascension is possible) or the rank 3 in the control groups (baseline TP1 compared to TP2-4 when rank 4 is removed and group size is adjusted) (Suppl. Figure 3). In A. percula, cooperative behaviours were significantly lower in rank 4 during the early treatment time point 2, compared to the rank 3 baseline time point $(\mathrm{TP} 1$, estimate $=-0.465$, c. $\mathrm{i} .=-0.917,-0.012)$ and control time points (TP2, estimate $=-0.47$, c. $\mathrm{i} .=-0.922,-0.017$, and TP4, estimate $=-0.536$, c. $\mathrm{i} .=-1.001,-0.072)$. In contrast, the frequency of cooperative behaviours of rank 4 during the later treatment time points (24h/48h after rank 3 removal, TP3/TP4), were not significantly different from the cooperations recorded for rank 3 during the baseline or control time points (Suppl. Figure 3). In A. perideraion, 

groups or rank 3 in the control groups at any time point (Suppl. Figure 3).

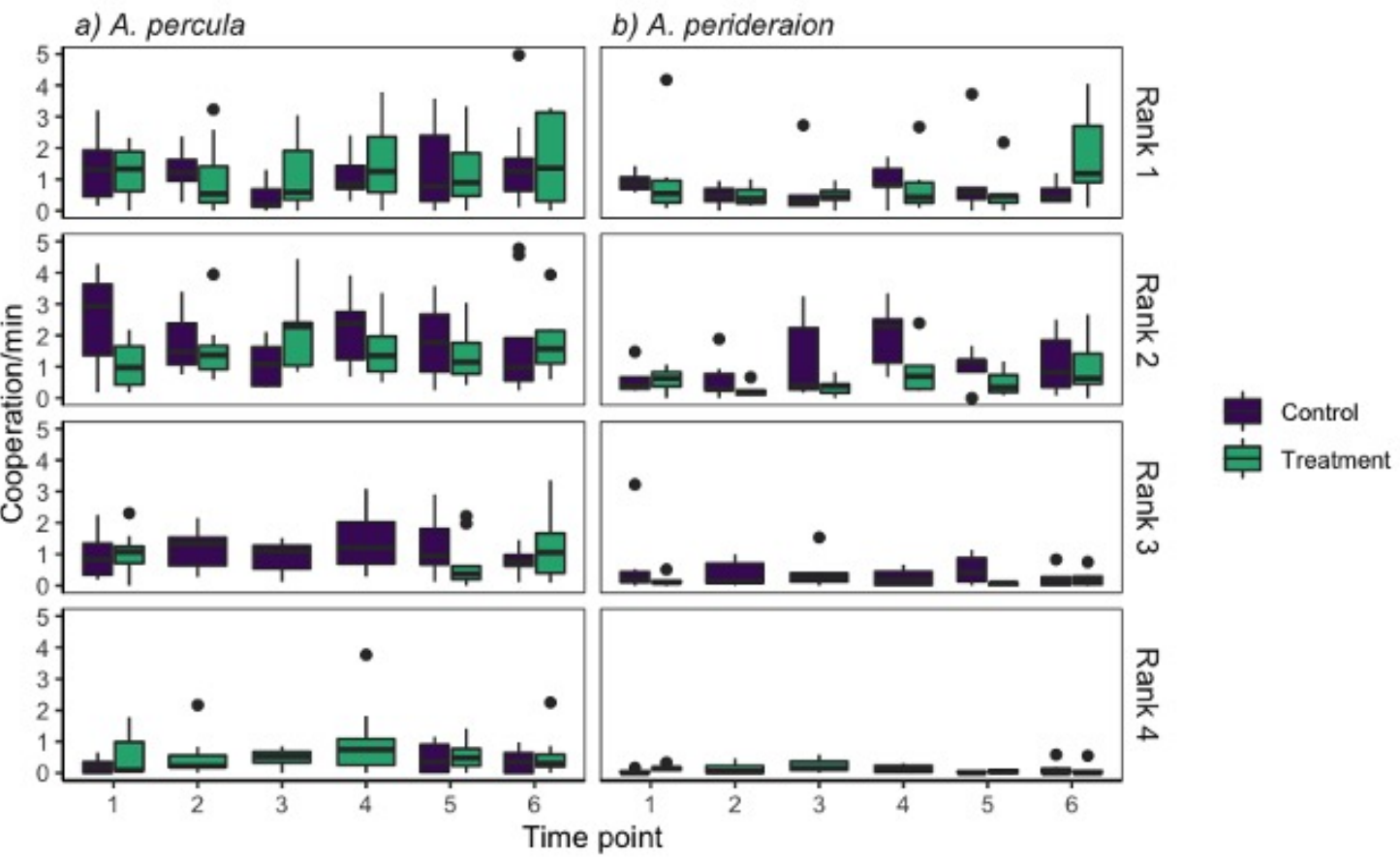

428

429

430

431

432

433

434

435

436

437

438

439

440

441

Figure 8. Cooperative behaviours per minute ('Cooperation/min') in groups of a) Amphiprion percula $(\mathrm{n}=20)$ and b) A. perideraion $(\mathrm{n}=12)$, for each rank in the size hierarchy (rank $1-4)$, time point (1-6) and treatment group (purple: Control, green: Treatment) of the rank ascension experiment (central bar: median; boxes: lower and upper quartiles; whiskers: $+/-1.5 * I Q R$ (interquartile range)).

\section{Discussion}

We show that there are differences in levels of aggression and cooperation among ranks in anemonefish size hierarchies, and that these behaviours are likely adaptive since they change in a predictable way as individuals ascend in rank. While species differed in overall levels of aggression recorded, we found consistently higher frequencies of aggression in higher ranks (more dominant individuals) in both species. Our results thus confirm predictions about increased aggression with higher rank and larger group size (Cant et al., 2006a) and are in line with findings 
442 in other fish organized in dominance hierarchies (Colleter \& Brown, 2011; Dey et al 2013).

443 However, our results do not confirm predictions that lower ranks should perform more cooperative

444 behaviours (Cant \& Field, 2001; 2005). Focussing just on the subordinates, we found the highest

445 ranked subordinate (rank 3) performed most of the cooperative behaviours as well as aggressive

446 behaviours. For cooperative effort, our results are very close to what is predicted when basal

447 mortality rate is stable but the cost of helping effort increases for lower ranks (see Cant \& Field,

448 2005). Since the dominance hierarchy in anemonefishes is organized by size, smaller ranks may

449 not be able to bear the cost of cooperative behaviours, as has been found in some birds, mammals

450 and other fishes (Boland et al., 1997; Clutton-Brock et al., 2000; Heinsohn \& Legge, 1999).

451 Taborsky (1984) demonstrated the cost of helping in a cooperatively breeding cichlid, by showing

452 that subordinates performing cooperative behaviours grew slower than those that did not

453 cooperate. In our study, smaller ranks spent more time performing submissive behaviours and the

454 lowest ranks did not perform many of the behaviours observed in the higher ranks. Instead, they

455 were seemingly occupied with feeding and avoiding other group members (T Rueger, pers. obs.),

456 presumably in order to avoid eviction (Buston, 2003c). Thus, our results show the importance of

457 studying aggressive and cooperative behaviours simultaneously and for each individual rank, and

458 the importance of extending empirical testing to systems where individuals are not related.

459 We found some evidence for rank ascension within only a couple of days in both species of

460 anemonefishes when the opportunity was experimentally created. Aggressive behaviours

461 increased in rank 4 when rank 3 was removed and were comparable to those recorded for rank 3

462 in the control groups, where group size changes were accounted for. Also, while cooperative

463 behaviours did not significantly increase, some upward trend was evident. The slight increase in

464 cooperative behaviours, particularly cleaning and other interactions with the anemone, could be 
'prestige signalling', similar to what has been recorded in the freshwater cichlid Neolamprologus pulcher, where the individual indicates its value by helping to improve territory quality (see review in Wong \& Balshine, 2011). At the same time, the aggressive reaction of all group members towards the reintroduced fish (either rank 3 or rank 4) could be a punishment for leaving the group or being 'idle'. Similar reactions to experimentally removed and reintroduced individuals have been recorded in N. pulcher (Balshine et al 1998; Fisher et al., 2014) and fairy wrens (Mulder \& Langmore, 1993). Interestingly, aggression was directed from the rank 4 individuals towards the reintroduced, larger rank 3 individuals, suggesting that perceived rank ascension took place over a short time span (48hrs). However, since the experimental duration was insufficient to allow rank 4 individuals to grow and bridge the gap in total body length, initial protests appeared to be over quickly, with both rank 3 and 4 individuals present in their original ranks and aggressions subsiding $24 \mathrm{hrs}$ after reintroduction. Longer experiments involving growth rate measurements would be useful for understanding rank ascension and punishment structures in more detail. In any case, the current study shows that behaviours differ and change consistently among ranks and hence such variation is likely to be viewed as adaptive.

Our findings contribute to the growing body of literature disentangling the causes of sociality in groups of unrelated vertebrates. For anemonefishes, the reasons for subordinates to stay in groups of non-relatives and forego reproduction have been found to range from future fitness benefits through territory inheritance (Buston, 2004a), to the presence of social constraints (Buston, 2003c; Rueger et al., 2018) and environmental constraints (Branconi et al., 2020). However, why dominants tolerate unrelated, non-breeding subordinates has remained unclear, since subordinates have not been shown to directly increase dominant reproductive output, at least in the short term (Buston, 2004b). Here however, we provide evidence to show that subordinates do perform 
cooperative behaviours, and hence a reason why breeders tolerate them. These behaviours, namely the cleaning and massaging of the anemone and deterrent of anemone predators, are likely cooperative as they invoke a temporary decrease in subordinate fitness (time and energy expenditure that could be focused on other activities such as feeding) and yet provide indirect benefit to dominants. From the subordinate's perspective, there is minimal relatedness among group members (Buston et al., 2007) and therefore no inclusive fitness to be gained through helping. Rather, cooperative effort is likely to be beneficial as it increases the quality of the territory (anemone) which in turn increases survival, access to resources and later inheritance of a higher quality territory (Kokko et al., 2001; Kingma et al., 2014). Since a substantial proportion of the cooperative behaviours observed in this study involved interacting with the anemone, it is likely that enhancement of territory quality is a key benefit of cooperation. In addition, since subordinates stand to inherit the territory upon death of the dominants, these cooperative behaviours directed towards the anemone could enhance the quality of the anemone territory, generating direct future benefits to helpful subordinates.

Interestingly, when comparing the two species that are closely related and share a very similar ecology, we found some distinct differences in the degree to which specific behaviours were displayed. The causes of higher aggression in A. perideraion compared to A. percula are not known but may be partially related to smaller size differences between the lower ranks in A. perideraion compared to $A$. percula (T Rueger, pers obs.). Size ratios are known to vary with respect to position in the hierarchy (Buston \& Cant 2006; Wong, 2011). When lower ranks are closer in size, as is observed in $A$. perideraion, individuals may need to be more aggressive to protect their rank from those closer in size. While the cause of the interspecific differences in aggression observed here is unknown, future studies should consider the influence of size ratios on behavioural patterns in 
511 species with size-based dominance hierarchies. A. perideraion females have also been observed

512 leaving large groups and forcefully taking over neighbouring anemones (Rueger et al., 2018),

513 suggesting that elevated aggressiveness of $A$. perideraion could simply be a fixed trait of this

514 species. Additionally, A. perideraion exhibited lower levels of cooperation (territory maintenance

515 and defence) than $A$. percula, with more time being occupied with intragroup behavioural

516 interactions. Higher levels of cooperation from subordinates in $A$. percula may indicate a more

517 cohesive, efficient group structure and at the individual level could indicate that stricter conflict

518 resolution mechanisms are at play. Future research should focus on the nuanced differences

519 between species and explore the ecological factors that may lead closely related species of

520 anemonefishes to pursue different social strategies and show different behavioural frequencies.

521 Conclusion

522 Our interspecific comparative study has shown strong support for some theoretical predictions

523 pertaining to variation in aggression levels between ranks in animal groups with dominance

524 hierarchies, but we also found theory-contradicting results pertaining to levels of cooperative

525 behaviours. This shows the importance of testing the generality of theory based on groups of

526 relatives using animals living in groups of unrelated individuals. Another important aspect of this

527 study was the quantification of subordinate behaviours that are helpful to the group and/or territory.

528 Although we did not observe alloparental broodcare, we did find significant levels of cooperative

529 behaviours in subordinates which are likely to have long-term impacts on the fitness of dominant

530 breeders via effects on the anemone host. This contributes to the evidence expanding our view of

531 sociality. Finally, we show that there are interspecific differences in aggressive and cooperative

532 behaviours between closely related species. These differences warrant further investigation using 
broader comparative approaches in a wider range of species and likely represent the next frontier in sociality research.

535

536

537

538

539

540

541

542

543

544

545

546

547

548

549

550

551

552

553

554

555

556

557

558

\section{Acknowledgements}

We thank the Tamare-Kilu communities for granting access to their reefs for this study. We thank

Nelson Sikatua, Jerry Sikatua, Catheline Froehlich and Selma Klanten for field assistance and Chancey MacDonald for help with the artwork. Fieldwork was supported by Mahonia Na Dari Research and Conservation Centre, Kimbe Bay, Papua New Guinea.

\section{Funding}

This study was funded by the Sea World Research and Rescue Foundation SWR/11/2018 and funds awarded to M. Wong by the Centre for Sustainable Ecosystems Solutions, at the University of Wollongong.

\section{Ethics}

This study was approved by the University of Wollongong Animal Ethics Committee, permit number AE18/06.

\section{References}

Balshine-Earn, S., F. C. Neat, H. Reid, and M. Taborsky. 1998. Paying to stay or paying to breed? Field evidence for direct benefits of helping behavior in a cooperatively breeding fish. Behavioral Ecology 9:432-438.

Balshine, S., B. Leach, F. Neat, H. Reid, M. Taborsky, M., and N. Werner. 2001. Correlates of group size in a cooperatively breeding cichlid fish (Neolamprologus pulcher). Behavioral Ecology and Sociobiology 50: 134-140.

Bates, D., M. Maechler, B. Bolker, and S. Walker. 2015. Fitting Linear Mixed-Effects Models Using lme4. Journal of Statistical Software, 67: 1-48.

Boland, C. R. J., R. Heinsohn, and A. Cockburn. 1997. Experimental manipulation of brood reduction and parental care in cooperatively breeding white-winged choughs. Journal of Animal Ecology 66: 683-691. 
Bourke, A. F. 2011. Principles of social evolution. Oxford University Press.

Buston, P. M. 2003a. Social hierarchies: size and growth modification in clownfish. Nature 424: 145-146.

Buston, P. M. 2003b. Forcible eviction and prevention of recruitment in the clown anemonefish. Behavioral Ecology 14: 576-582

Buston, P. M. 2004a. Territory inheritance in clownfish. Proceedings of the Royal Society of London. Series B: Biological Sciences 271: S252-S254.

Buston, P. M. 2004b. Does the presence of non-breeders enhance the fitness of breeders? An experimental analysis in the clown anemonefish Amphiprion percula. Behavioral Ecology and Sociobiology 57: 23-31.

Buston, P. M., and M.A. Cant. 2006. A new perspective on size hierarchies in nature: patterns, causes, and consequences. Oecologia 149:362-372.

Buston, P. M., S. M. Bogdanowicz, A. Wong, and R. G. Harrison. 2007. Are clownfish groups composed of close relatives? An analysis of microsatellite DNA variation in Amphiprion percula. Molecular Ecology 16: 3671-3678.

Branconi, R., T. A. Barbasch, R. K. Francis, M. Srinivasan, G. P. Jones, and P. M. Buston. 2020. Ecological and social constraints combine to promote evolution of non-breeding strategies in clownfish. Communications biology 3:1-7.

Canestrari, D., J. M. Marcos, and V. Baglione. 2005. Effect of parentage and relatedness on the individual contribution to cooperative chick care in carrion crows Corvus corone corone. Behavioral Ecology and Sociobiology 57: 422-428.

Cant, M. A. 2000. Social control of reproduction in banded mangooses. Animal Behaviour 59: $147-158$.

Cant, M. A., and J. Field. 2001. Helping effort and future fitness in cooperative animal societies. Proceedings of the Royal Society of London. Series B: Biological Sciences 268: 1959-1964.

Cant, M. A., and J. Field. 2005. Helping effort in a dominance hierarchy. Behavioral Ecology 16: $708-715$.

Cant, M. A., J. B. Llop, and J. Field. 2006a. Individual variation in social aggression and the probability of inheritance: theory and a field test. The American Naturalist 167: 837-852.

Cant, M. A., S. English, H. K. Reeve, and J. Field. 2006b. Escalated conflict in a social hierarchy. Proceedings of the Royal Society B: Biological Sciences. 273:2977-2984.

Cant, M. A., S. J. Hodge, M. B. Bell, J. S. Gilchrist, and H. J. Nichols. 2010. Reproductive control via eviction (but not the threat of eviction) in banded mongooses. Proceedings of the Royal Society B: Biological Sciences 277: 2219-2226.

Chausson, J., M. Srinivasan, and G. P. Jones. 2018. Host anemone size as a determinant of social group size and structure in the orange clownfish (Amphiprion percula). PeerJ 6: e5841.

Clutton-Brock, T. H., P. N. M. Brotherton, M. J. O’Riain, and A. S. Griffin. 2000. Individual 
600

601

602

603

604

605

606

607

608

609

610

611

612

613

614

615

616

617

618

619

620

621

622

623

624

625

626

627

628

629

630

631

632

633

contributions to babysitting in a cooperative mongoose Suricata suricatta. Proceedings of the Royal Society B: Biological Sciences 267: 301-305.

Clutton-Brock, T. H., S. J. Hodge, and T. P. Flower. 2008. Group size and the suppression of subordinate reproduction in Kalahari meerkats. Animal Behaviour 76: 689-700.

Colléter, M., and C. Brown. 2011. Personality traits predict hierarchy rank in male rainbowfish social groups. Animal Behaviour 81: 1231-1237.

Cronin, A., and J. Field. 2007. Social aggression in an age-dependent dominance hierarchy. Behaviour. 144:753-765.

Dey, C. J., A. R. Reddon, C. M. O’Connor, and S. Balshine. 2013. Network structure is related to social conflict in a cooperatively breeding fish. Animal Behaviour. 85:395-402.

Emlen, S. T. 1982. The evolution of helping. I. An ecological constraints model. The American Naturalist 119: 29-39.

Fautin, D. G. 1992. Field guide to anemonefishes and their host sea anemones. Western Australian Museum, Perth

Field, J., A. Cronin, and C. Bridge. 2006. Future fitness and helping in social queues. Nature 441: 214-217.

Fischer, S., M. Zöttl, F. Groenewoud, and M. B. Taborsky. 2014. Group-size-dependent punishment of idle subordinates in a cooperative breeder where helpers pay to stay. Proceedings of the Royal Society B: Biological Sciences 281: 20140184.

Friard, O., and M. Gamba. 2016. BORIS: a free, versatile open-source event-logging software for video/audio coding and live observations. Methods in Ecology and Evolution 7: 1325-1330.

Fricke, H. W. 1979. Mating System, Resource Defence and Sex Change in the Anemonefish Amphiprion akallopisos. Zeitschrift fuer Tierpsychologie 50: 313-326.

Fricke, H., and S. Fricke. 1977. Monogamy and sex change by aggressive dominance in coral reef fish. Nature 266: 830-832

Iwata, E., and J. Manbo. 2013. Territorial behaviour reflects sexual status in groups of false clown anemonefish (Amphiprion ocellaris) under laboratory conditions. Acta Ethol 16: 97-103.

Johnson, P. C. D. 2014. Extension of Nakagawa \& Schielzeth's R2 GLMM to random slopes models. Methods in Ecology and Evolution 5: 944-946.

Heinsohn, R., and S. Legge, S. 1999. The cost of helping. Trends in Ecology \& Evolution 14: 53-57.

Heg, D., Z. Heg-Bachar, L. Brouwer, and M. Taborsky. 2008. Experimentally induced helper dispersal in colonially breeding cooperative cichlids. Environmental Biology of Fishes 83: 191-206.

Hamilton, W. D. 1963. The evolution of altruistic behavior. The American Naturalist 97: 354356. 
Hamilton, W. D. 1964. The genetical evolution of social behaviour. II. Journal of theoretical biology 7: 17-52.

Holbrook, S. J., and R. J. Schmitt. 2005. Growth, reproduction and survival of a tropical sea anemone (Actiniaria): Benefits of hosting anemonefish. Coral Reefs 24: 67-73.

Jandt, J. M., S. Bengston, N. Pinter-Wollman, J. N. Pruitt, N. E. Raine, A. Dornhaus, and A. Sih. (2014). Behavioural syndromes and social insects: personality at multiple levels. Biological Reviews. 89:48-67.

Kingma, S. A., P. Santema, M. Taborsky, and J. Komdeur. 2014. Group augmentation and the evolution of cooperation. Trends in Ecology and Evolution. 29: 476-484.

Koenig, W. D., and F. A. Pitelka. 1979. Relatedness and inbreeding avoidance: counterploys in the communally nesting acorn woodpecker. Science, 206: 1103-1105.

Kokko, H., \& Johnstone, R. A. 1999. Social queuing in animal societies: a dynamic model of reproductive skew. Proceedings of the Royal Society of London. Series B: Biological Sciences 266: 571-578.

Kokko, H., Johnstone R. A., and T. H. Clutton-Brock. 2001. The evolution of cooperative breeding through group augmentation. Proceedings of the Royal Society of London. Series B: Biological Sciences 268: 187-196.

Le Vin, A. L., B. K. Mable, M. Taborsky, D. Heg, and K. E. Arnold. 2011. Individual variation in helping in a cooperative breeder: relatedness versus behavioural type. Animal Behaviour 82: 467-477.

Lüdecke, D., M. Dominique, P. Waggoner, and I. Patil. 2020. performance: Assessment of Regression Models Performance. $\mathrm{R}$ package version 0.4.6. https:/CRAN.Rproject.org $/$ package $=$ performance

Mariscal, R. N. 1966. The symbiosis between tropical sea anemones and fishes: a review. The Galapagos 157-171.

Mulder, R. A., and N. E. Langmore. 1993. Dominant males punish helpers for temporary defection in superb fairy-wrens. Animal Behaviour 45: 830-833.

Nakagawa, S., and H. Schielzeth. 2013. A general and simple method for obtaining R2 from generalized linear mixed-effects models. Methods in Ecology and Evolution 4: 133-142.

Nakagawa, S., P. C. D. Johnson, and H. Schielzeth. 2017. The coefficient of determination R2 and intra-class correlation coefficient from generalized linear mixed-effects models revisited and expanded. Journal of The Royal Society Interface 14: 20170213.

Queller, D. C. 1994. Genetic relatedness in viscous populations. Evolutionary Ecology 8: 70-73.

Ross, R. M. 1978. Territorial behavior and ecology of the anemonefish Amphiprion melanopus on Guam. Ethology 46: 71-83.

Rueger, T., T. A. Barbasch, M. Y. Wong, M. Srinivasan, G. P. Jones, and P. M. Buston. 2018. 
692

693

694

695

696

697

698

Reproductive control via the threat of eviction in the clown anemonefish. Proceedings of the Royal Society of London. Series B: Biological Sciences 285: 20181295.

Sakamoto, Y., M. Ishiguro, and G. Kitagawa. 1986. Akaike information criterion statistics. Dordrecht, The Netherlands: D. Reidel, 81.

Shreeves, G., and J. Field. 2002. Group size and direct fitness in social queues. The American Naturalist 159: 81-95.

Stiver, K. A., J. Fitzpatrick, J. K. Desjardins, and S. Balshine. 2006. Sex differences in rates of territory joining and inheritance in a cooperatively breeding cichlid fish. Animal Behaviour 71: 449-456.

Taborsky, M. \& Limberger, D. 1981. Helpers in fish. Behavioral Ecology and Sociobiology 8: $143-145$.

Taborsky, M. 1984. Broodcare helpers in the cichlid fish Lamprologus brichardi: their costs and benefits. Animal Behaviour 32: 1236-1252.

Thavarajah, N. K., M. Fenkes, and T. H. Clutton-Brock. 2014. The determinants of dominance relationships among subordinate females in the cooperatively breeding meerkat. Behaviour. 151:89-102.

West-Eberhard, M. J. 1975. The evolution of social behavior by kin selection. The Quarterly Review of Biology 50: 1-33.

Woolfenden, G. E., and J. W. Fitzpatrick. 1978. The inheritance of territory in group-breeding birds. Bioscience 28: 104-108.

Wong, M. Y. 2011. Group size in animal societies: The potential role of social and ecological limitations in the group-living fish, Paragobiodon xanthosomus. Ethology 117: 638-644.

Wong, M. Y., and S. Balshine. 2011. The evolution of cooperative breeding in the African cichlid fish, Neolamprologus pulcher. Biological Reviews 86: 511-530.

Wright, J., P. G. Parker, and K. J. Lundy. 1999. Relatedness and chick-feeding effort in the cooperatively breeding Arabian babbler. Animal Behaviour 58: 779-785. 